\title{
New core-pyrene m structure organophotocatalysts usable as highly efficient photoinitiators
}

\author{
Sofia Telitel ${ }^{1}$, Frédéric Dumur ${ }^{2}$, Thomas Faury ${ }^{2}$, Bernadette Graff ${ }^{1}$, \\ Mohamad-Ali Tehfe ${ }^{1}$, Didier Gigmes ${ }^{*}$, Jean-Pierre Fouassier ${ }^{3}$ \\ and Jacques Lalevée ${ }^{* 1}$
}

Open Access

\author{
Full Research Paper \\ Address: \\ ${ }^{1}$ Institut de Science des Matériaux de Mulhouse IS2M - UMR 7361 - \\ UHA; 15, rue Jean Starcky, F-68057 Mulhouse Cedex, France, \\ ${ }^{2}$ Aix-Marseille Université, CNRS, Institut de Chimie Radicalaire, UMR \\ 7273, F-13397 Marseille, France and ${ }^{3}$ ENSCMu- \\ UHA, 3 rue Alfred Werner, F-68093 Mulhouse Cedex, France \\ Email: \\ Didier Gigmes* - didier.gigmes@univ-amu.fr; Jacques Lalevée* - \\ jacques.lalevee@uha.fr \\ * Corresponding author \\ Keywords: \\ cationic photopolymerization; free-radical-promoted cationic \\ photopolymerization; photocatalysts; photoinitiators; radical \\ photopolymerization
}

\author{
Beilstein J. Org. Chem. 2013, 9, 877-890. \\ doi:10.3762/bjoc.9.101 \\ Received: 02 March 2013 \\ Accepted: 12 April 2013 \\ Published: 07 May 2013 \\ This article is part of the Thematic Series "Organic free radical chemistry". \\ Guest Editor: C. Stephenson \\ (c) 2013 Telitel et al; licensee Beilstein-Institut. \\ License and terms: see end of document.
}

\begin{abstract}
Eleven di- and trifunctional compounds based on a core-pyrene $\pi$ structure (Co_Py) were synthesized and investigated for the formation of free radicals. The application of two- and three-component photoinitiating systems (different Co_Pys with the addition of iodonium or sulfonium salts, alkyl halide or amine) was investigated in detail for cationic and radical photopolymerization reactions under near-UV-vis light. The proposed compounds can behave as new photocatalysts. Successful results in terms of rates of polymerization and final conversions were obtained. The strong MO coupling between the six different cores and the pyrene moiety was studied by DFT calculations. The different chemical intermediates are characterized by ESR and laser flash photolysis experiments. The mechanisms involved in the initiation step are discussed, and relationships between the core structure, the Co_Py absorption property, and the polymerization ability are tentatively proposed.
\end{abstract}

\section{Introduction}

Free radical sources are encountered in various areas such as organic chemistry, biochemistry and polymer chemistry. In the field of polymer photochemistry applied to photopolymerization reactions, they are referred to as photoinitiators (PI) [1]. These PIs are usable in two scenarios, both of which are light induced. Firstly, they are usable in free radical polymerization
(FRP), where the PIs work as either cleavable type I PIs or uncleavable type II PIs in dependence of couples formed by the $\mathrm{PI}$ and hydrogen or electron donors ( $\mathrm{r} 1$ in Scheme 1). Secondly, PIs may be used in free-radical-promoted cationic polymerization (FRPCP), in which the produced radical $\mathrm{R}^{\bullet}$ is oxidized by an onium salt, e.g., $\mathrm{Ar}_{2} \mathrm{I}^{+}$, to form $\mathrm{Ar}_{2} \mathrm{I}^{\bullet}$ and a cation $\mathrm{R}^{+}$suit- 
$\mathrm{PI}(h v) \longrightarrow \mathrm{Pl}^{*} \longrightarrow \mathrm{R}$ and $\mathrm{R}+$ monomer $\rightarrow$ polymer $(\mathrm{r} 1)$

$\mathrm{R}^{*}+\mathrm{Ar}_{2} \mathrm{I}^{+} \longrightarrow \mathrm{R}^{+}+\mathrm{Ar}_{2} \mathrm{I}^{\cdot} \longrightarrow \mathrm{R}^{+}+\mathrm{Arl}+\mathrm{Ar}^{*}$

and $\mathrm{R}^{+}+$monomer $\rightarrow$ polymer

$\mathrm{Pl}^{*}+\mathrm{Ar}_{2} \mathrm{I}^{+} \longrightarrow \mathrm{Pl}^{+}+\mathrm{Ar}_{2} l^{*}$

and $\mathrm{Pl}^{+}+$monomer $\rightarrow$ polymer

(r3)

Scheme 1: Typical reactions for photoinitiated cationic polymerization.

able for the ROP reaction. The $\mathrm{Ar}_{2} \mathrm{I}^{\bullet}$ species is readily decomposed into ArI and $\mathrm{Ar}^{\circ}$ ( $\mathrm{r} 2$ in Scheme 1). There is also an usual cationic polymerization (CP; r3 in Scheme 1) [1,2]. When the PIs exhibit a catalytic behavior analogous to a photocatalyst (PC) in organic chemistry, they are designed as photoinitiator catalysts (PIC). PIs as well as PICs are based on pure organic, that is, metal free, or organometallic compounds. In the presence of additives, they constitute a photoinitiating system (PIS).

Among others, two points of interest in the photopolymerization area are (i) the reactivity and efficiency of the PIs and PICs and (ii) the irradiation conditions. Indeed, the absorption properties (wavelengths $\lambda$, molar extinction coefficients $\varepsilon$ ), the excited-state processes, the reactivity of the produced radicals, and the characteristics of the light sources (emission spectra, available luminous power density) govern the polymerization efficiency (rate of polymerization, final monomer conversion).
The photopolymerization reactions in radiation curing technologies are often carried out under high-intensity light sources $\left(>1000 \mathrm{~mW} \mathrm{~cm}^{-2}\right)$. Applications in this area and in other fields may require to avoid the use of UV rays delivered by $\mathrm{Hg}$ lamps or to irradiate with visible light $(400-700 \mathrm{~nm})$ and low photon fluxes $\left(\sim 2-10 \mathrm{~mW} \mathrm{~cm}^{-2}\right)$. Recent works have aimed at working under soft irradiation conditions (near-UV-vis light, low light intensity), which allows the use of Xe lamps, laser diodes, solar radiation, household halogen lamps, fluorescent bulbs and blue, green and white LEDs (see a recent review in [1]).

New high-performance PIs and PICs are continuously being developed [1-10] through the design of novel structures (e.g., novel chromophores, novel cleavable bonds) and the modification ofexisting structures by using the classical introduction of electron-donating or -withdrawing substituents, conjugated groups or moieties, and more complex changes on the skeleton (see typical recent examples in [11-41]). To meet the challenge of designing efficient PIs and PICs under soft irradiation, we have recently started the search for suitable multifunctional arrangements exhibiting a strong coupling of the molecular orbitals MOs [42,43]. Improved absorption properties (redshifted $\lambda$, higher $\varepsilon$ ) while keeping a high reactivity have been already achieved. Examples of these investigated architectures (Scheme 2) [42-44] are linked PI-PI units (e.g., PI = pyrene) or PI-PI' (e.g., PI = pyrene and PI' = 2,2'-dimethoxy-2-phenylace-

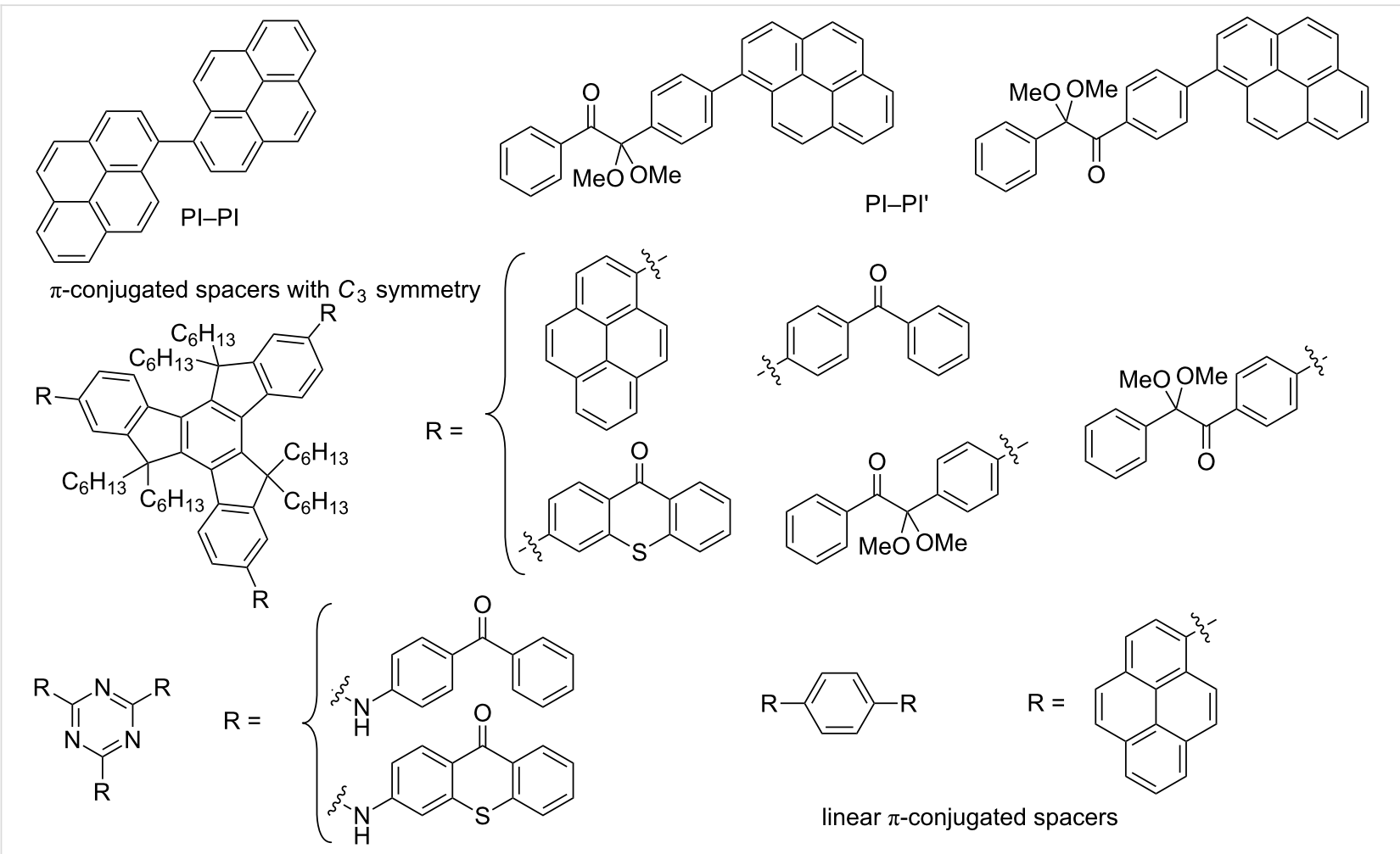


tophenone) and PI moieties (e.g., PI = benzophenone, thioxanthone, 2,2'-dimethoxy-2-phenylacetophenone, pyrene) linked to a trifunctional core (truxene, triazine, benzene); the same could be expected by using a difunctional core.

In the present paper, we consider a series of eleven di- and trifunctional core-pyrene $\pi$ compounds Co_Py, where the pyrene moiety is used as a PI. The cores include a functional- ized truxene (Py_5), several substituted phenyl rings (Py_2, Py_3, Py_4, Py_9, Py_10) two functionalized triazines (Py_7, Py_12), a triphenylamine (Py_6), a carbazole (Py_11) and a benzothiadiazole (Py_8) (Scheme 3). The idea is to get a high absorption around 380-410 nm where Xe-Hg lamps, Xe lamps, LED, laser diodes and even household halogen lamps are usable. The large choice of Co_Pys should allow for studying the effect of the core on the MO coupling and the resulting<smiles></smiles>

Py_1<smiles></smiles>

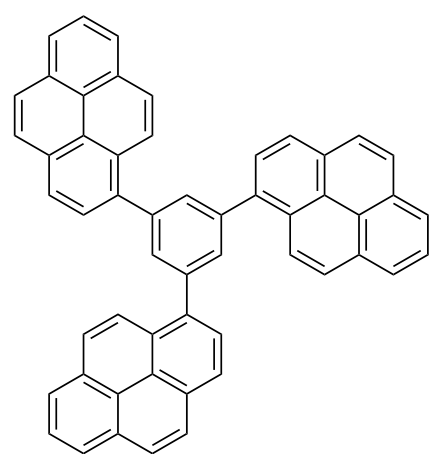

Py_3<smiles></smiles>

Py_4<smiles>C=CC(=C)c1ccc2ccc3cccc4ccc1c2c34</smiles><smiles>C=C(/C=C\C)/C=C\C(=C)C(=C)c1ccc(N(/C(C)=C/C)c2ccc(-c3ccc4ccc5cccc6ccc3c4c56)cc2)cc1</smiles>

Py_6<smiles>Cc1ccc(-c2nc(-c3ccc(-c4ccc5ccc6cccc7ccc4c5c67)cc3)nc(-c3ccc(-c4ccc5ccc6cccc7ccc4c5c67)cc3)n2)cc1</smiles>

Py_7

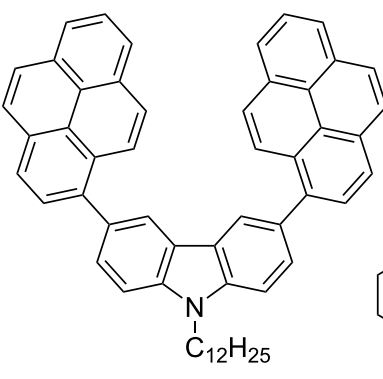

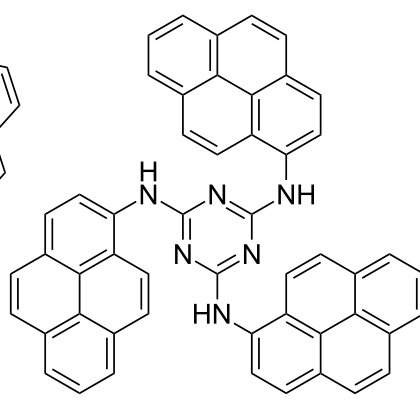

Py 11

Py_12 
<smiles>CN(CCO)CCO</smiles>

MDEA<smiles>OCCOc1ccc(C2(c3ccccc3)c3ccccc3Sc3ccccc32)cc1</smiles>

$\mathrm{TH}$<smiles>O=C(CBr)c1ccccc1</smiles>

$\mathrm{PBr}$<smiles>C=CC(=O)OCC(CC)(COC(=O)C=C)COC(=O)C=C</smiles>

TMPTA<smiles>C=Cn1c2ccccc2c2ccccc21</smiles>

NVK<smiles>O=C(OCC1CCC2OC2C1)C1CCC2OC2C1</smiles>

EPOX<smiles>Cc1ccc([Hg]c2ccc(C(C)C)cc2)cc1</smiles><smiles>Fc1c(F)c(F)c(P)c(F)c1F</smiles>

iod<smiles>C[Si](C)(C)O[Si](C)(C)O[Si](C)(C)O[Si](C)(C)CCC1CCC2CC1O2</smiles>

EPOX-Si

Scheme 4: Other chemical compounds.

absorption properties. The activity of these Co_Py compounds in the FRP of acrylates and the FRPCP (and eventually the cationic polymerization $\mathrm{CP}$ ) of epoxides through a ring-opening polymerization (ROP) under exposure to the near-UV-vis light delivered by a $\mathrm{Hg}-\mathrm{Xe}$ lamp $\left(\sim 30 \mathrm{~mW} \mathrm{~cm}^{-2}\right)$ and the visible light of a halogen lamp (soft irradiation conditions; $\sim 10 \mathrm{~mW} \mathrm{~cm}{ }^{-2}$ ) is investigated. The Co_Pys are used in combination with additives: iodonium or sulfonium salts for ROP and amine or/and alkyl halide for FRP. The monomers investigated are given in Scheme 4. The mechanisms are analyzed by electron spin resonance (ESR), steady-state photolysis, fluorescence and laser flash photolysis (LFP). The ability of Co_Pys to behave as new organophotocatalysts is also discussed.

\section{Results and Discussion Light absorption, redox properties and MO calculations}

The UV absorption spectra of the different pyrene derivatives are depicted in Figure 1. The solvents were selected for good solubility of the Co Pys. Absorption maxima are located at $\sim 350$ nm for Py_2, Py_3, Py_4, Py_5, Py_12, Py_8, Py_9, Py_10, Py_11, 370 nm for Py_6, Py_7, and $330 \mathrm{~nm}$ for Py_1 (Table 1). This corresponds to a red shift of the absorption for
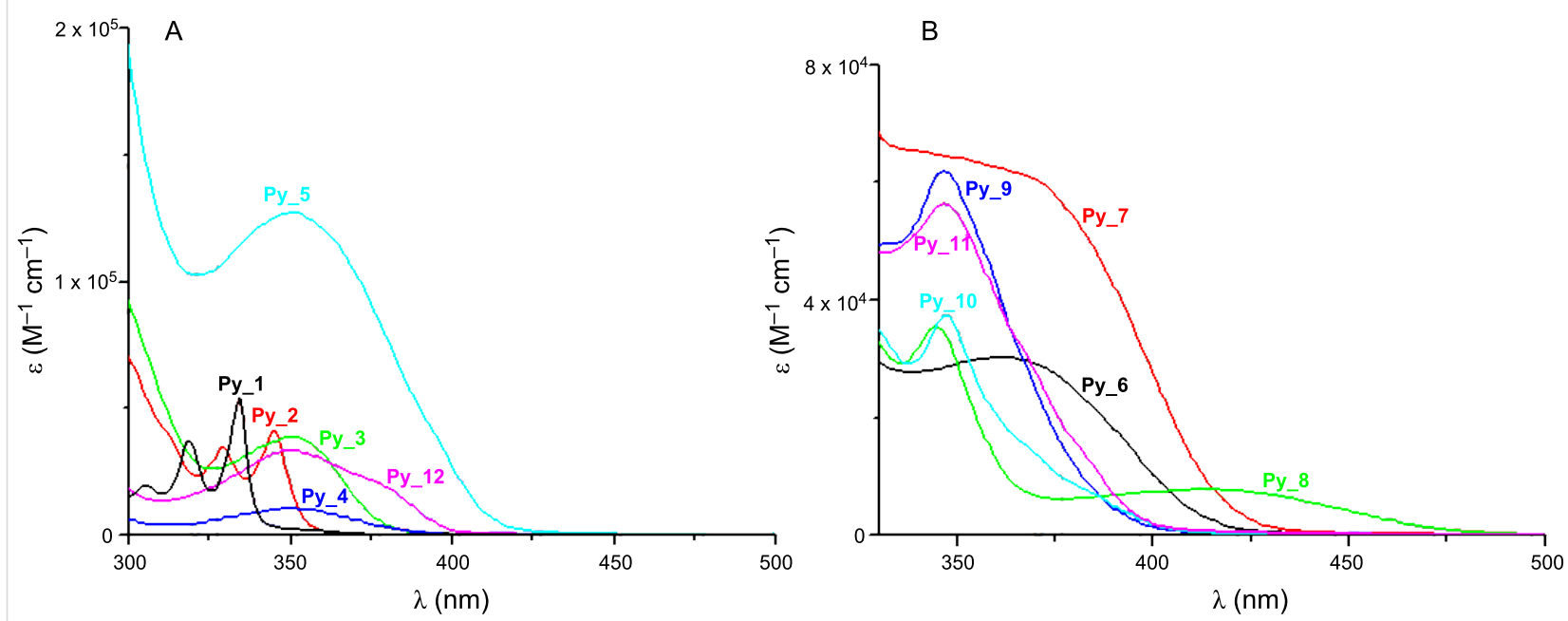

Figure 1: UV-vis absorption spectra of the investigated compounds: (A) In acetonitrile for Py_1 and acetonitrile/toluene (50/50) for the other molecules, (B) in toluene. 
Table 1: Properties of the pyrene derivatives in acetonitrile $\left(^{*}\right)$ and toluene. Light absorption and emission properties (experimental $\lambda_{\text {max,abs,exp }}$ and calculated $\lambda_{\text {max,abs,calc }}$ maximum absorption wavelengths, emission wavelengths $\lambda_{\text {max,em}}$ ), excited-state energy levels ( $E_{\mathrm{S}}$ ), oxidation potentials ( $\left.E_{\mathrm{ox}}\right)$ and free-energy changes $\Delta G$ (see text) [1].

\begin{tabular}{|c|c|c|c|c|c|c|c|}
\hline & $\begin{array}{c}\lambda_{\text {max,abs,exp }} \\
(\mathrm{nm})\end{array}$ & $\begin{array}{c}\lambda_{\max , \text { abs,calc }}{ }^{a} \\
(\mathrm{~nm})\end{array}$ & $\begin{array}{l}\lambda_{\max , e m} \\
(\mathrm{~nm})\end{array}$ & $\begin{array}{c}E_{\mathrm{ox}} \\
(\mathrm{V} / \mathrm{SCE})\end{array}$ & $\begin{array}{c}E_{S} \\
(e V)\end{array}$ & $\begin{array}{c}\Delta G_{\mathrm{PBr}} \\
(\mathrm{eV})\end{array}$ & $\begin{array}{c}\Delta G_{\text {lod }} \\
(\mathrm{eV})\end{array}$ \\
\hline Py_1* & 334 & $327(f=0.27)$ & 393 & 1.33 & 3.44 & -1.33 & -1.9 \\
\hline Py_2 & 344 & $334(f=0.41)$ & 380 & 0.8 & 3.45 & -1.87 & -2.45 \\
\hline Py_3 & 351 & $356(f=0.50)$ & 393 & 0.9 & 3.36 & -1.68 & -2.26 \\
\hline Py_4 & 351 & $373(f=0.3)$ & 423 & 0.6 & 3.21 & -1.83 & -2.41 \\
\hline Py_5 & 353 & $387(f=1.16)$ & 404 & 0.7 & 3.24 & -1.76 & -2.34 \\
\hline Py_6 & 365 & $\begin{array}{l}344(f=0.52) \\
403(f=0.74)\end{array}$ & 441 & 0.9 & 3.04 & -1.36 & -1.94 \\
\hline Py_7 & 367 & $344(f=0.68)$ & 440 & - & 3.02 & - & - \\
\hline Py_8 & 344 & $365(f=0.39)$ & 530 & 0.7 & 2.6 & -1.12 & -1.7 \\
\hline Py_9 & 346 & $336(f=0.44)$ & 428 & 0.8 & 3.2 & -1.62 & -2.2 \\
\hline Py_10 & 347 & $376(f=0.51)$ & 425 & 0.9 & 3.2 & -1.52 & -2.1 \\
\hline Py_11 & 346 & $370(f=0.4)$ & 409 & - & 3.22 & - & - \\
\hline Py_12 & 346 & $377(f=1.00)$ & 397 & 0.6 & 3.22 & -1.84 & -2.42 \\
\hline
\end{tabular}

aMolecular orbital MO calculations (using the time-dependent density functional theory at B3LYP/6-31G* level on the relaxed geometries calculated at UB3LYP/6-31G* level); $f=$ oscillator strength.

Py_2 to Py_12 compared to the reference compound Py_1. At $365 \mathrm{~nm}$, the maximum emission wavelength of the $\mathrm{Hg}-\mathrm{Xe}$ lamp, the molar extinction coefficients $\varepsilon_{\max }$ of the different Co_Pys follow the order Py_5 $>$ Py_7 $>$ Py_11 $>$ Py_9 $>$ Py_6 $>$ Py_12 $>$ Py_3 $>$ Py_10 $>$ Py_8 $>$ Py_4 $>$ Py_1 $=$ Py_2. The highest $\varepsilon_{\max }$ is obtained for Py_5 $\left(\varepsilon_{353}=13 \times 10^{4} \mathrm{M}^{-1} \mathrm{~cm}^{-1}\right.$, $\varepsilon_{346}=6 \times 10^{4} \mathrm{M}^{-1} \mathrm{~cm}^{-1}$ versus $\varepsilon_{334}=6 \times 10^{4} \mathrm{M}^{-1} \mathrm{~cm}^{-1}$ for Py_5, Py_9 and Py_1, respectively). Py_4 exhibits low $\varepsilon$ values, and thus a low efficiency can be expected for this compound.

The oxidation potentials of the Co_Pys (Table 1) range from 1.33 V (Py_1) to 0.6 V (Py_4, Py_12). The singlet-state energy is also affected by the core of the structure, i.e., $2.6 \mathrm{eV}$ for $\mathbf{P y} \_\mathbf{8}$ versus $3.44 \mathrm{eV}$ for the reference Py_1. The free-energy change $\Delta G$ of the Co_Py/phenacyl bromide $\mathrm{PBr}$ (or the iodonium salt, Iod) interaction is very favorable $(\Delta G<<0)$. Py_2 exhibits the most favorable $\Delta G \mathrm{~s}:-2.45 \mathrm{eV}$ (Iod) and $-1.87 \mathrm{eV}(\mathrm{PBr})$.

MO calculations show that the calculated and experimental values (Table 1) are approximately the same, e.g., a difference of 5 to $10 \mathrm{~nm}$ is observed for Py_2 and Py_3. The oscillator strengths (noted $\mathrm{f}$ in Table 1) are higher for the new proposed structures than for Py_1 in agreement with their better light absorption properties (Figure 1). A strong coupling of the $\pi$ MOs of the core with those of the pyrene substituents is shown supporting a clear $\pi \pi^{*}$ character of the HOMO-LUMO transition, as evidenced in Figure 2 for the investigated derivatives. For the various $\pi$-core/pyrene substituent combinations, different coupling strengths can be observed (Figure 2). Strong couplings of the MOs lead to red-shifted transitions compared to Py_1 and enhanced absorption coefficients (Figure 1), e.g., for Py_3, Py_5, Py_6, Py_8, Py_11 and Py_12. A strong delocalization of the HOMOs and LUMOs is observed in line with their better absorption properties. For Py_2, the coupling is weak and the absorption properties are moderately affected compared to Py_1.

\section{Photochemical reactivity Fluorescence experiments}

A strong quenching of the Co_Py singlet states by $\mathrm{PBr}$, amine (MDEA), Iod and the sulfonium salt TH is found. Py_3 is selected for this mechanistic study (Figure 3) because of the high reactivity of this compound in photopolymerization experiments (see below). The rate constants in that case are $1.5 \times$ $10^{10}, 9 \times 10^{9}, 1 \times 10^{10}$ and $3.7 \times 10^{9} \mathrm{M}^{-1} \mathrm{~s}^{-1}$, respectively. The ${ }^{1} \mathbf{P y} \_3 / \mathrm{PBr},{ }^{1} \mathbf{P y} \_3 / \operatorname{Iod}$ and ${ }^{1} \mathbf{P y} \_3 / \mathrm{TH}$ interactions are diffusioncontrolled in full agreement with the highly favorable $\Delta G$ s (Table 1; the reduction potential for $\mathrm{TH}$ is $-1.3 \mathrm{~V}$ [1]; the calculated $\Delta G$ is $-1.16 \mathrm{eV}$ ). They correspond to an efficient electron transfer followed by the usual fast generation of radicals from the radical anion species (r5-r7 in Scheme 5) or an electron/ proton transfer with the amine (r8 in Scheme 5).

\section{ESR spin trapping experiments}

In ESR spin trapping experiments upon UV light exposure, the interaction of the Co_Pys with the iodonium salt Iod (Figure 4A) or the sulfonium salt TH (Figure 1 in Supporting Information File 1) leads to an aryl radical Ar (e.g., hyperfine coupling constants $h f c s$ of the PBN adduct: $\mathrm{a}_{\mathrm{N}}=14.2 \mathrm{G}$ and $\mathrm{a}_{\mathrm{H}}$ 


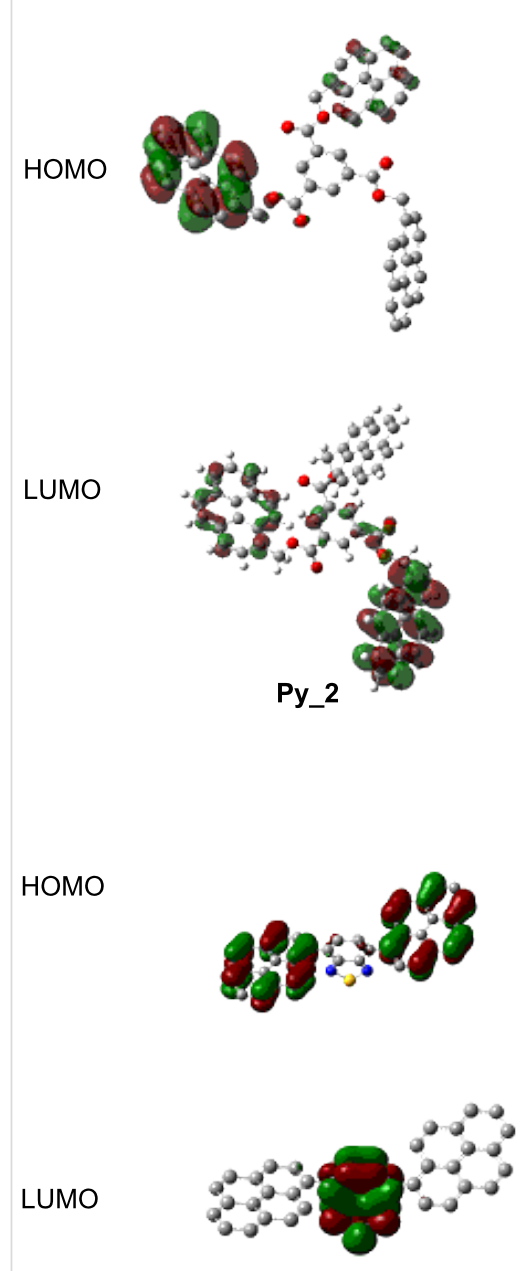

Py_8
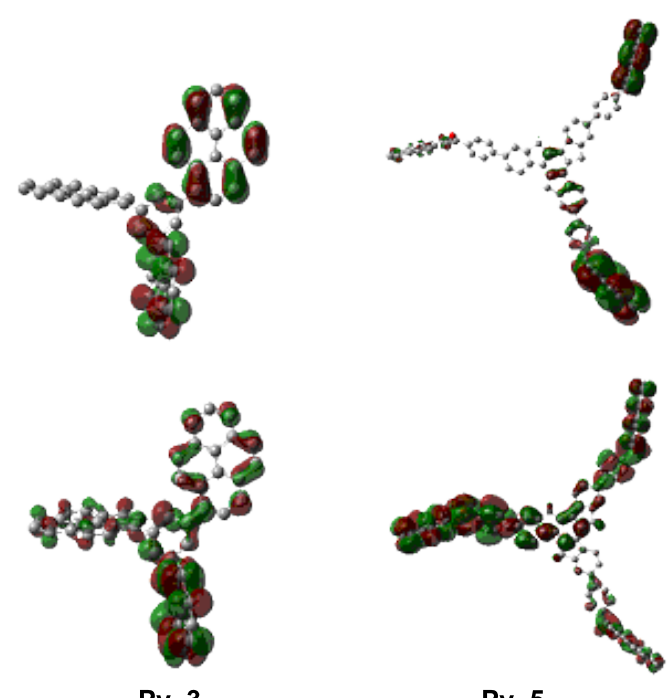

Py_3

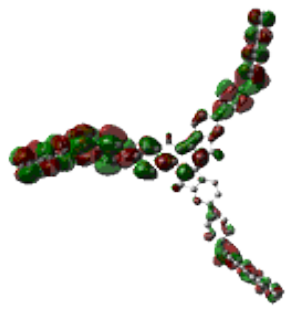

Py_5
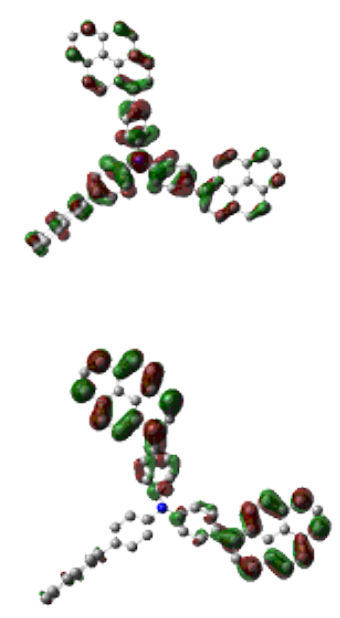

Py_6
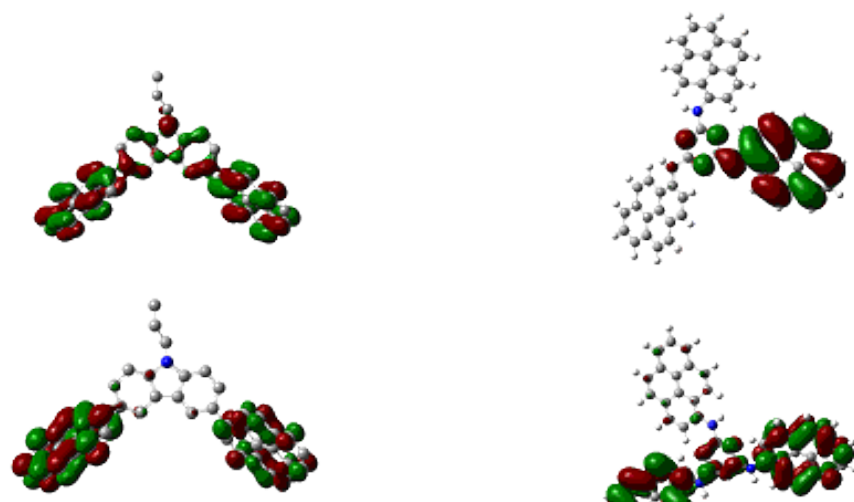

Py_11

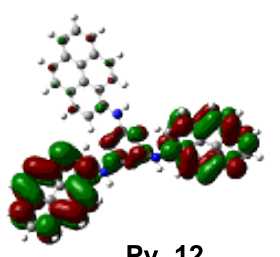

Py_12

Figure 2: HOMO-LUMO orbitals for Py_2, Py_3, Py_5, Py_6, Py_8, Py_11 and Py_12 involved in the $\Pi-\Pi^{*}$ transition (calculated at UB3LYP/6-31G* level; for Py_5 and Py_11, the alkyl chains have been simplified to reduce the computational cost).

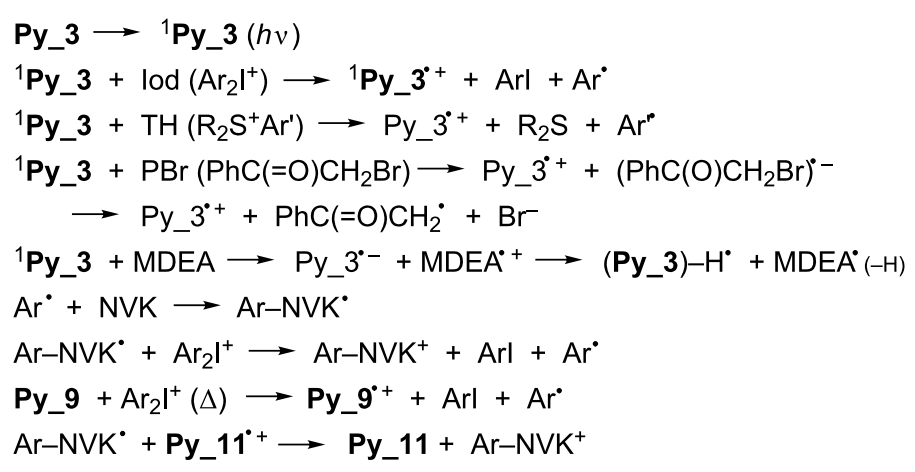




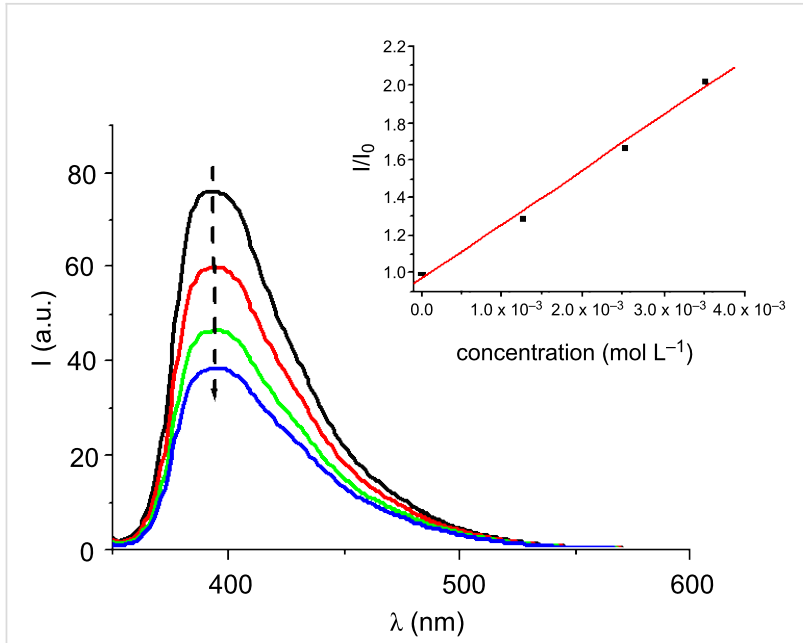

Figure 3: Fluorescence quenching of ${ }^{1} \mathrm{Py} \_3$ by the phenacylbromide $(\mathrm{PBr})$ in acetonitrile/toluene (50/50). Insert: Stern-Volmer plot (the concentrations used are given in this plot).

$=2.2 \mathrm{G}$ in agreement with known data $[22-25,45])$ in line with (r5). In the same way, phenacyl radicals and $\alpha$-aminoalkyl radicals ( $r 7$ and $\mathrm{r} 8$ in Scheme 5) are observed in ${ }^{1} \mathbf{P y} \_\mathbf{3} / \mathrm{PBr}$ and ${ }^{1}$ Py_3/EDB $\left(\mathrm{a}_{\mathrm{N}}=14.6 \mathrm{G}, \mathrm{a}_{\mathrm{H}}=4.5 \mathrm{G}\right.$ and $\mathrm{a}_{\mathrm{N}}=14.3 \mathrm{G}, \mathrm{a}_{\mathrm{H}}=2.5$ $\mathrm{G}$, respectively; Figure 4B and Figure 4C; ethyldimethylaminobenzoate (EDB) instead of MDEA is used to avoid a high polarity of the sample preventing an ESR investigation). The $\mathbf{P y} \_$3/Iod or the $\mathbf{P y} \_3 /$ TH couple generates a cation radical $\left(\mathbf{P y} \_\mathbf{3}^{\cdot+}\right)$ that can initiate a cationic polymerization whereas the phenacyl and aminoalkyl radicals formed in $\mathbf{P y} \_\mathbf{3} / \mathrm{PBr}$ or $\mathbf{P y} \_\mathbf{3}$ / MDEA are susceptible to radical polymerization.

\section{Laser flash photolysis}

Upon laser excitation of $\mathbf{P y} \_\mathbf{3}$ at $355 \mathrm{~nm}$, a triplet state $\mathrm{T}_{1}$ characterized by a maximum absorption at $\sim 420 \mathrm{~nm}$ and a rather long lifetime is formed ( $t>4 \mu \mathrm{s}$ ) (Figure S2 in Supporting Information File 1). This $\mathrm{T}_{1}$ state is similar to that of Py_1 [31].
The short $\mathrm{S}_{1}$ lifetime (e.g., $\sim 55$ ns under $\mathrm{N}_{2}$ for Py_3) and the diffusion controlled interactions of $\mathrm{S}_{1}$ with Iod, $\mathrm{PBr}$ or MDEA (see above) prevent a significant production of $\mathrm{T}_{1}$ in Co_Py/Iod ( $\mathrm{PBr}$ or MDEA). Therefore, a triplet-state pathway can be neglected in the investigated systems.

\section{Thermal processes}

For some Co_Py/Iod couples, a slow thermal redox process can also occur. Indeed, in ESR-ST experiments, aryl radicals are generated without irradiation within $24 \mathrm{~h}$ (no free radical was observed in Py_9 or Iod alone). For example, in Py_9/Iod, the same radicals as in $\mathrm{r} 5$ are produced (Figure $5 ; h f c c \mathrm{~s}: \mathrm{a}_{\mathrm{N}}=14.2$ $\mathrm{G}$ and $\mathrm{a}_{\mathrm{H}}=2.2 \mathrm{G}$ for the PBN radical adduct). Peroxyl radicals are also observed, as aryls easily add to $\mathrm{O}_{2}\left(\mathrm{a}_{\mathrm{N}}=13.3 \mathrm{G}\right.$ and $\mathrm{a}_{\mathrm{H}}$ $=1.6 \mathrm{G}$ for the PBN radical adduct, in agreement with [45]). As in $r 5$ in Scheme 5, a cation radical Py_9 ${ }^{\bullet+}$ is concomitantly formed. This thermal process is slow as $E_{\mathrm{Ox}}\left(\mathbf{P y} \_9\right)>E_{\text {red }}(\operatorname{Iod})$ (Table 1). The formation of radical cations can be worthwhile to initiate cationic polymerization at room temperature (see below).
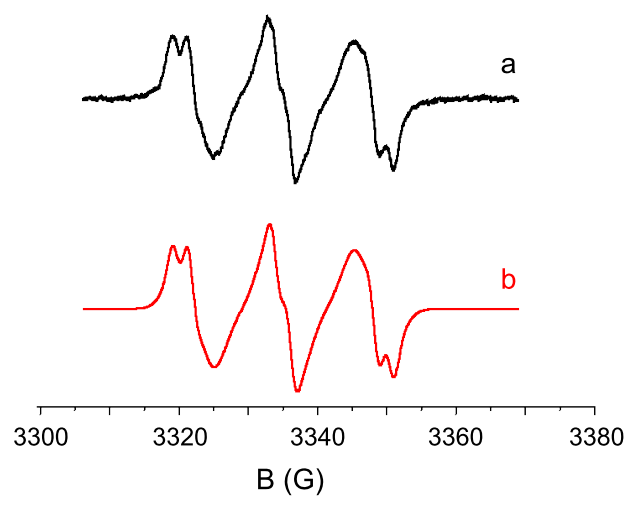

Figure 5: ESR-spin trapping spectra of Py_9/lod in tert-butylbenzene (storage at rt for $24 \mathrm{~h}$ ); (a) experimental and (b) simulated spectra.
A

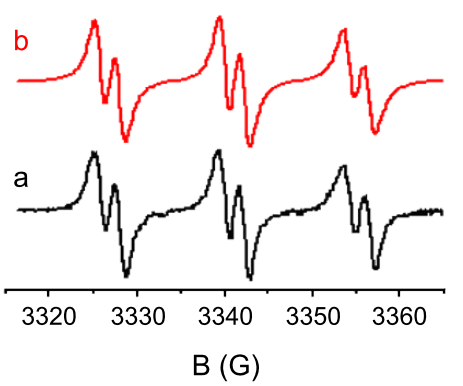

B

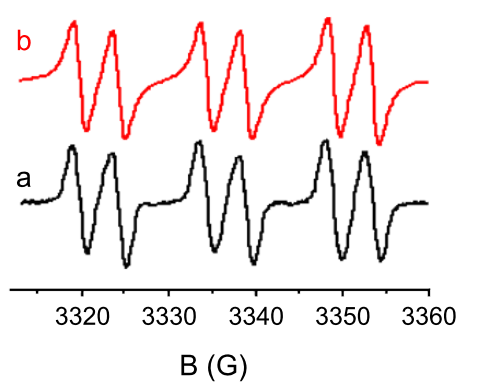

C
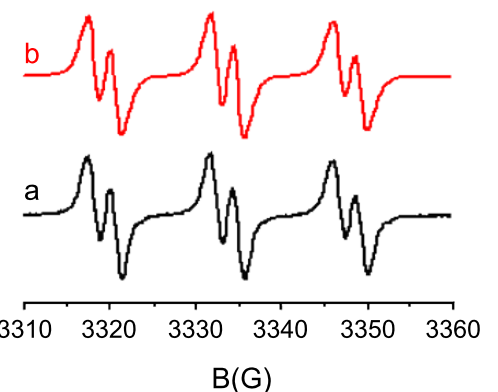

Figure 4: ESR spectra obtained upon irradiation of (A) Py_3/lod, (B) Py_3/PBr and (C) Py_3/EDB in tert-butylbenzene. Phenyl-N-tert-butylnitrone (PBN) is used as a spin trap; (a) experimental and (b) simulated ESR spectra. 

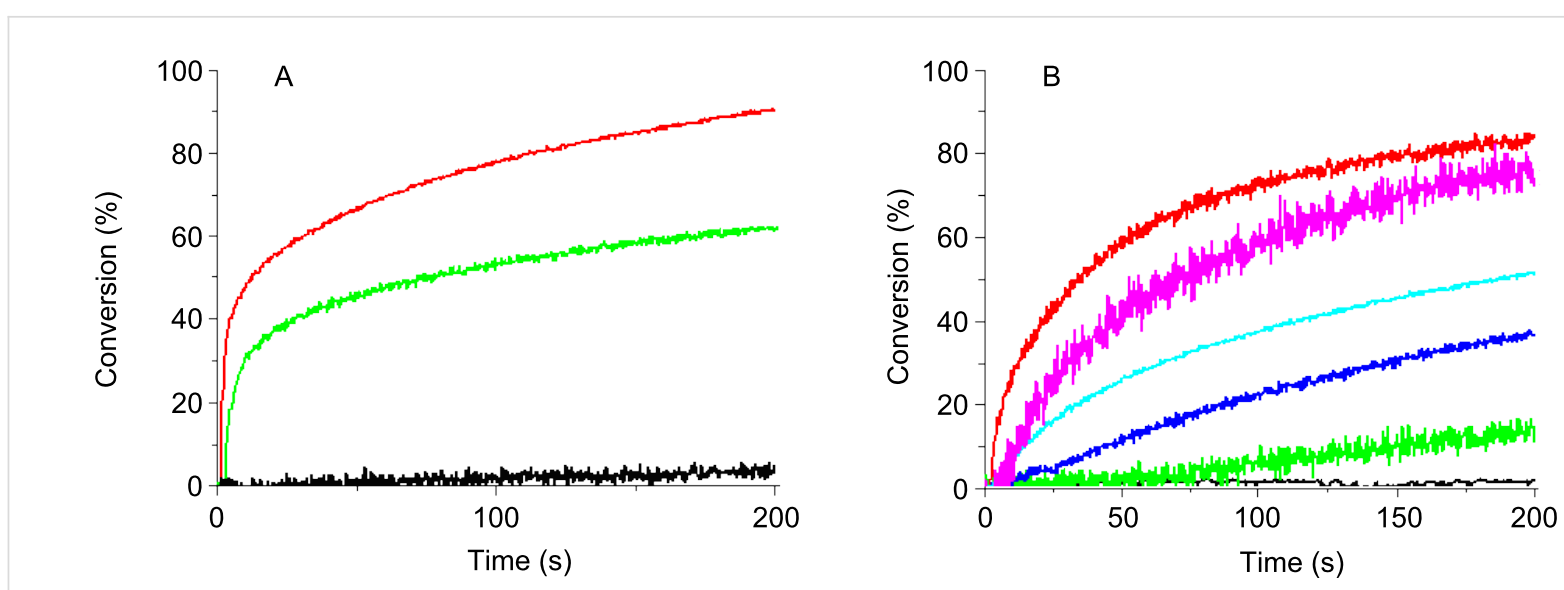

Figure 6: Photopolymerization profiles of EPOX upon Xe-Hg lamp irradiation $(\lambda>340 \mathrm{~nm}$ ) under air for different photoinitiating systems: (A) (a) lod (2\% w/w); (b) Py_3/lod (1\%/2\% w/w); (c) Py_1/lod (1\%/2\% w/w); (B) (a) TH (2\% w/w); (b) Py_3/TH $(0.2 \% / 2 \%$ w/w); (c) Py_8/TH (0.2\%/2\% w/w); (d) Py_9/TH $(0.2 \% / 2 \% \mathrm{w} / \mathrm{w}) ;($ e) Py_10/TH $(0.2 \% / 2 \% \mathrm{w} / \mathrm{w}) ;$ (f) Py_11/TH $(0.2 \% / 2 \% \mathrm{w} / \mathrm{w})$.

\section{Ability of the different pyrene structures in photopolymerization reactions Cationic photopolymerization (CP)}

The ring-opening polymerization profiles of EPOX upon exposure to the Xe-Hg lamp under air using two-component PISs are shown in Figure 6, Figure 7 and Figure 8. A comparison of the photopolymerization profiles using the Py_1 (to Py_12)/Iod couples (Figures 6-8) shows that the fastest polymerization rates (Rp) and the highest final conversion (conv) are obtained with Py_11/Iod and Py_3/Iod. No polymerization is observed in the presence of Iod alone Figure 6A and Figure 8A, curves a.) Py_3/Iod leads to a conv $\sim 90 \%$ (Figure $6 \mathrm{~A}$, curve b) compared to Py_1/Iod (conv $\sim 50 \%$; Figure 6A, curve c). Almost all the new proposed structures are better than the starting structure Py_1 (Figure 7, curve b). This highlights the interest of the present approach associated with the modification of the Py chromophore. CP can also be initiated in the presence of the sulfonium salt TH, e.g., with Py_3, Py_8, Py_9, Py_10 and Py_11 (Figure 6B). The conversions reach $80 \%$ and $75 \%$ with Py_3/TH and Py_11/TH, respectively (after 200 s light exposure). EPOX-Si can also be easily polymerized (Figure 8 ). Py_3/Iod (Figure 8A) is still efficient (conv $\sim 50 \%$ ).

In these systems, the Co_Py ${ }^{\cdot+}$ generated in r5,r6 (Scheme 5) can initiate the CP process. The relative efficiency of these Co_Py/ Iod (or TH) combinations will be affected by different parameters: (i) their relative light absorption properties, (ii) the quantum yields of radical or radical cation formation in the singlet state (the singlet state is predominant, see above), (iii) the rate constants for reactions $\mathrm{r} 5$ and $\mathrm{r} 6$ and (iv) the ability of $\mathrm{Co}_{-} \mathrm{Py}^{\bullet+}$ to initiate a ring-opening polymerization process Structure-reactivity relationships for the different derivatives can hardly be extracted. This is probably ascribed to a strong interplay between (i) to (iv).

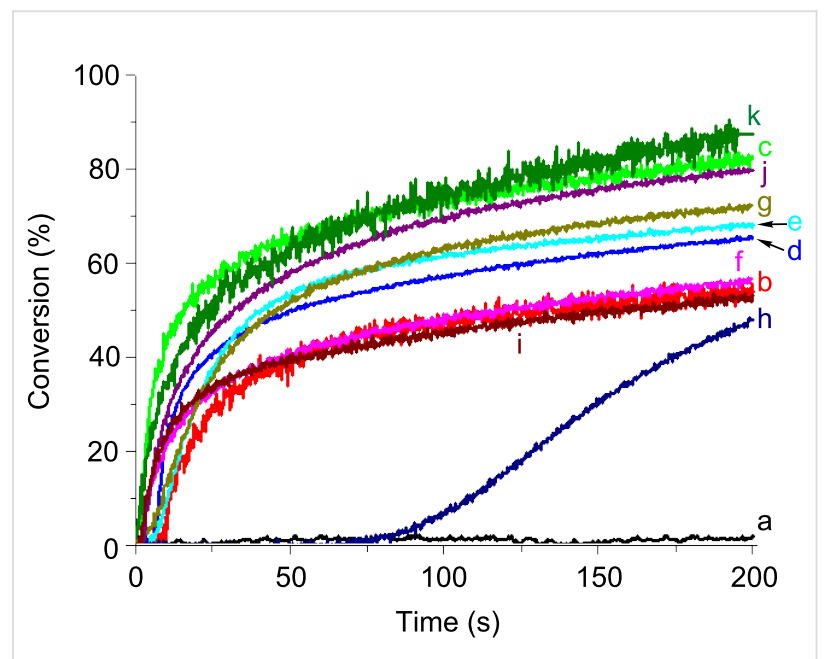

Figure 7: Photopolymerization profiles of EPOX upon a Xe-Hg lamp irradiation $(\lambda>340 \mathrm{~nm})$ under air for different photoinitiating systems: (a) lod $(2 \% \mathrm{w} / \mathrm{w})$; (b) Py_1/lod $(0.2 \% / 2 \% \mathrm{w} / \mathrm{w})$; (c) Py_3/lod $(0.2 \% / 2 \%$ w/w); (d) Py_4/lod (0.2\%/2\% w/w); (e) Py_5/lod (0.2\%/2\% w/w); (f) Py_6/lod $(0.2 \% / 2 \% \mathrm{w} / \mathrm{w})$; (g) Py_7/lod $(0.2 \% / 2 \% \mathrm{w} / \mathrm{w})$; (h) Py_8/lod (0.2\%/2\% w/w); (i) Py_9/lod (0.2\%/2\% w/w); (j) Py_10/lod $(0.2 \% / 2 \%$ w/w) ; (k) Py_11/lod $(0.2 \% / 2 \% \mathrm{w} / \mathrm{w})$.

A cationic photopolymerization profile of EPOX under very soft irradiation (halogen lamp exposure) is represented in Figure 8B. In the presence of Iod, several Co_Pys exhibiting an acceptable absorption at $\lambda>380 \mathrm{~nm}$ lead to efficient polymerization reactions. For example, conv $=40$ and $55 \%$ within $200 \mathrm{~s}$ with the Py_7/Iod and Py_11/Iod couples.

The three-component PIS (Py_11/Iod/NVK) (Figure 8B, curve 5) allows an increase of the EPOX conversion up to $75 \%$. A consumption of the NVK double bond is observed (Figure S3 in Supporting Information File 1). As known in other systems, this is accounted for by the addition of Ar to the NVK double bond 

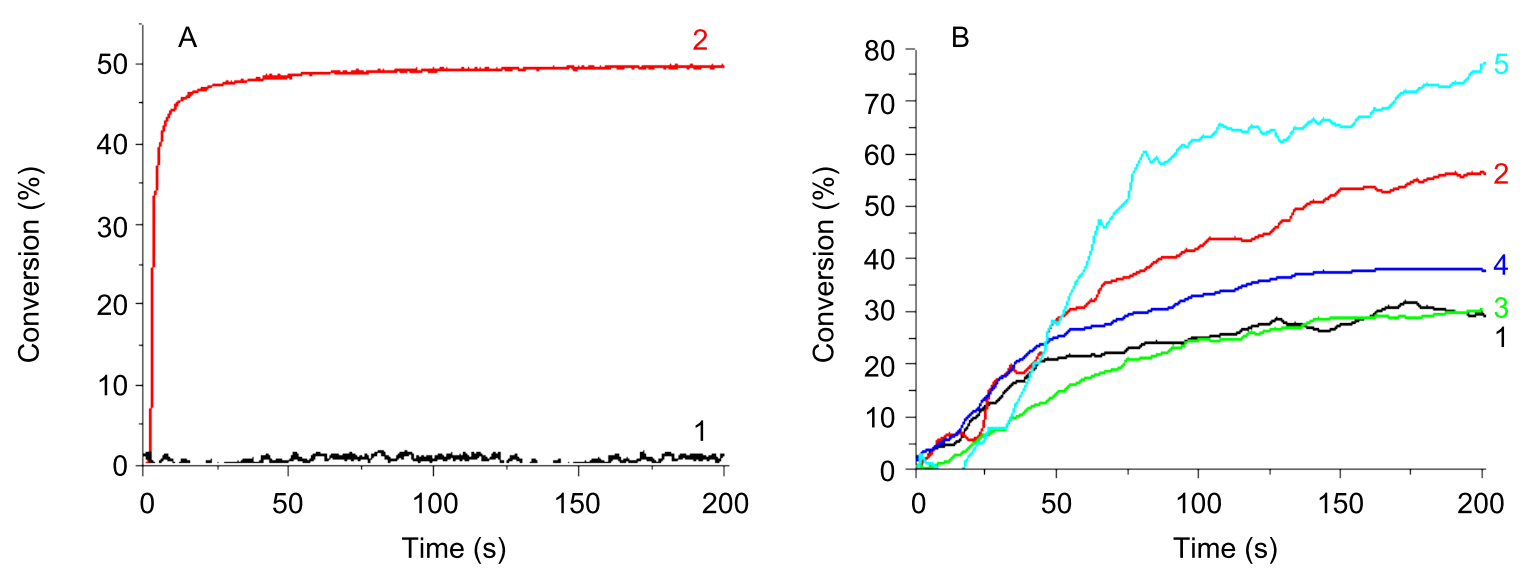

Figure 8: (A) Photopolymerization profiles of EPOX-Si upon a Xe-Hg lamp irradiation $(\lambda>340 \mathrm{~nm})$ under air for different photoinitiating systems: (A) (1) lod (2\% w/w); (2) Py_3/lod (1\%/2\% w/w); (B) Photopolymerization profiles of EPOX under air upon halogen-lamp irradiation in the presence of (1) Py_6/lod (0.2\%/2\% w/w); (2) Py_7/lod (0.2\%/2\% w/w); (3) Py_10/lod (0.2\%/2\% w/w); (4) Py_11/lod $(0.2 \% / 2 \%$ w/w); (5) Py_11/lod/NVK (0.2\%/2\%/ $2 \% \mathrm{w} / \mathrm{w})$.

(formation of an $\mathrm{Ar}-\mathrm{NVK}^{\bullet}$ radical) (r9 in Scheme 5). This electron rich radical is easily oxidized (r10 in Scheme 5) by Iod, the resulting cation $\mathrm{Ar}-\mathrm{NVK}^{+}$being able to initiate the cationic polymerization.

\section{Thermal polymerization at room temperature}

Remarkably, the thermal polymerization of EPOX can also be initiated by different Co_Py/Iod $(1 \% / 2 \% \mathrm{w} / \mathrm{w})$ systems. This reaction proceeds smoothly at $\mathrm{rt}$ but is completed after $24 \mathrm{~h}$, e.g., with Py_9, Py_6, Py_10 or Py_11/Iod, the final conversion is $>55 \%$. As supported by the ESR experiments (see above), the presence of, e.g., Py_9 ${ }^{\bullet+}$ explains the thermal initiation of the cationic polymerization of the epoxide ( 111 in
Scheme 5). For the other Co_Py, a good thermal stability is found. This dual behavior of some Co_Pys, which are able to initiate both a thermal and a photochemical cationic polymerization, can be very useful to initiate the polymerization in the shadow areas.

\section{Free radical photopolymerization (FRP)}

Typical free radical polymerization profiles of TMPTA upon the $\mathrm{Xe}-\mathrm{Hg}$ lamp exposure in laminate by using the Co_Py/ MDEA (or $\mathrm{PBr}$ ) two-component PISs are represented in Figure 9. In the presence of Co_Py alone, FRP occurs but the inhibition time is high and the final conversion is low $(50 \mathrm{~s}$; 35\% with Py_3). The addition of PBr (Figure 9A) or MDEA
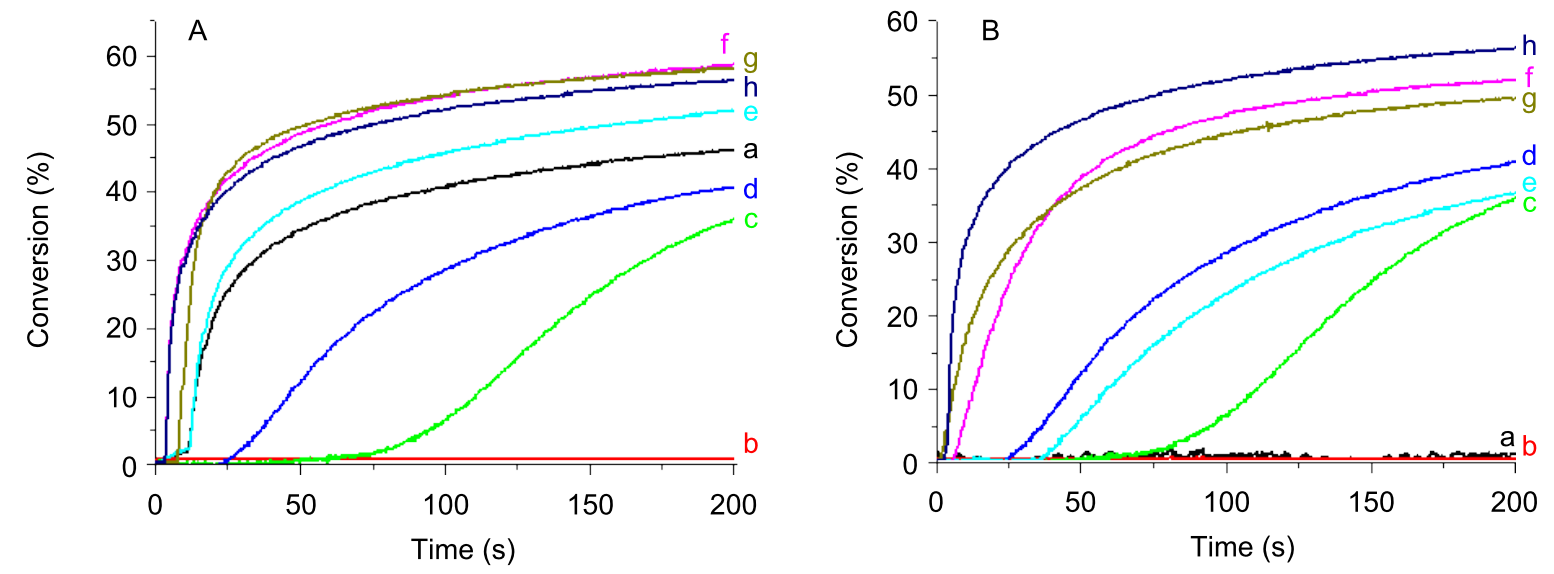

Figure 9: Photopolymerization profiles of TMPTA upon Xe-Hg lamp irradiation $(\lambda>340 \mathrm{~nm}$ ) in laminate for different photoinitiating systems: (A) (a) $\operatorname{PBr}(2 \%$ w/w); (b) Py_2 (0.2\% w/w); (c) Py_3 (0.2\% w/w); (d) Py_5 $(0.2 \%$ w/w); (e) Py_2/PBr $(0.2 \% / 2 \%$ w/w); (f) Py_3/PBr (0.2\%/2\% w/w); (g) Py_5/ $\operatorname{PBr}(0.2 \% / 2 \%$ w/w); (h) Py_3/MDEA/PBr (0.2\%/2\%/2\% w/w); (B) (a) MDEA (2\% w/w); (b) Py_2 (0.2\% w/w); (c) Py_3 (0.2\% w/w); (d) Py_5 (0.2\% w/ w); (e) Py_2/MDEA (0.2\%/2\% w/w); (f) Py_3/MDEA (0.2\%/2\% w/w); (g) Py_5/MDEA $(0.2 \% / 2 \%$ w/w); (h) Py_3/MDEA/PBr (0.2\%/2\%/2\% w/w). 

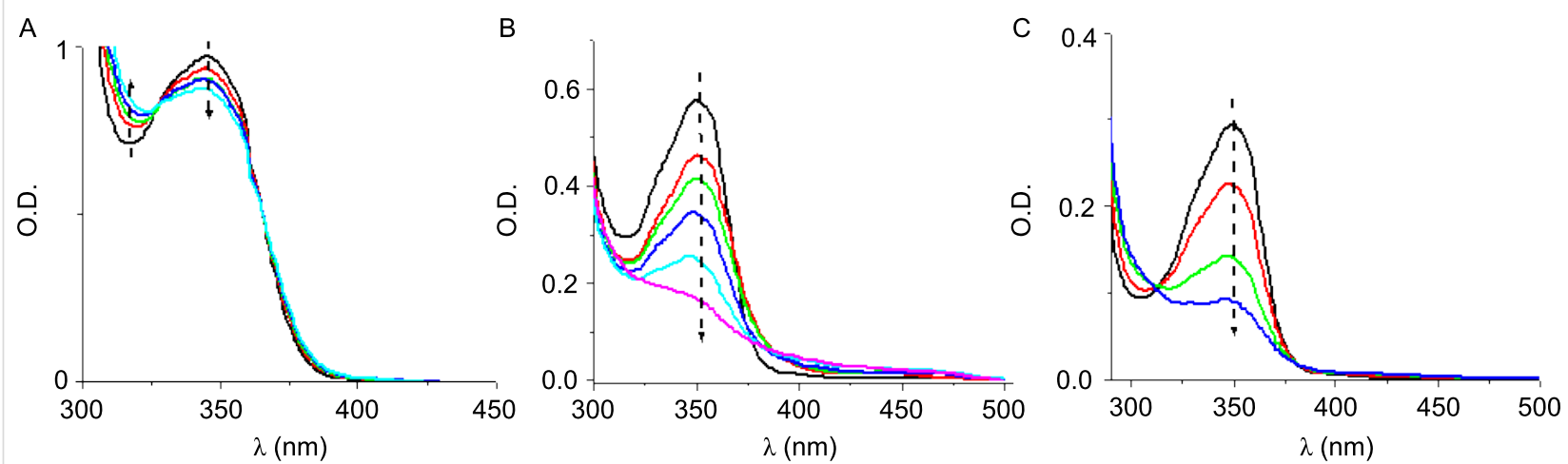

Figure 10: Photolysis of (A) the Py_3/PBr couple, (B) the Py_3/lod couple, and (C) the Py_3/MDEA couple; Xe-Hg lamp irradiation. In acetonitrile/ toluene (50/50); from $t=0$ to $5 \mathrm{~min}$.

(Figure 9B) shortens the inhibition time and increases the final conversion to $\sim 55 \%$. For the Co_Py/amine or Co_Py/PBr twocomponent systems, the radicals generated in $\mathrm{r} 7$ and $\mathrm{r} 8$ in Scheme 5 can initiate the FRP process. Due to its absorption in the $\mathrm{UV}, \mathrm{PBr}$ alone initiates the acrylate photopolymerization (conv $=45 \%$; Figure 9A, curve a). No striking improvement of the final conversion is observed when using the Py_3/MDEA/ $\mathrm{PBr}$ three-component PIS instead of Py_3/PBr ( 55\%; Figure 9A, curve f versus $\mathrm{h}$ ), but both Rp and conv are better when comparing to Py_3/MDEA.

\section{Photocatalyst behavior of the Co_Pys}

The photocatalytic behavior of the Co_Pys is investigated in the most interesting compounds reported above for the photopolymerization reactions. The steady-state photolysis of $\mathbf{P y} \_\mathbf{3} / \mathrm{PBr}$,
Py_3/Iod, Py_3/MDEA couples highlights the consumption of the pyrene moiety under light exposure (Figure 10). In Py_3/ $\mathrm{PBr}$ and Py_3/MDEA, isosbestic points are present at $330 \mathrm{~nm}$ (Figure 10A) and $315 \mathrm{~nm}$ (Figure 10B), respectively, suggesting stoichiometric reactions and no other side reactions.

The addition of NVK to Py_11/Iod shows that the photolysis is faster with Py_11/Iod than with Py_11/Iod/NVK couples (Figure 11A versus Figure 11B). This difference highlights that in the presence of NVK, Py_11 is regenerated according to an oxidation cycle (Scheme 6). Therefore, Py_11 behaves as a new photocatalyst in agreement with (r12 in Scheme 5).

In the Co_Py/PBr/MDEA three-component system, reactions $(\mathrm{r} 7, \mathrm{r} 8)$ are probably competitive (e.g., k[MDEA] $\sim \mathrm{k}[\mathrm{PBr}]$
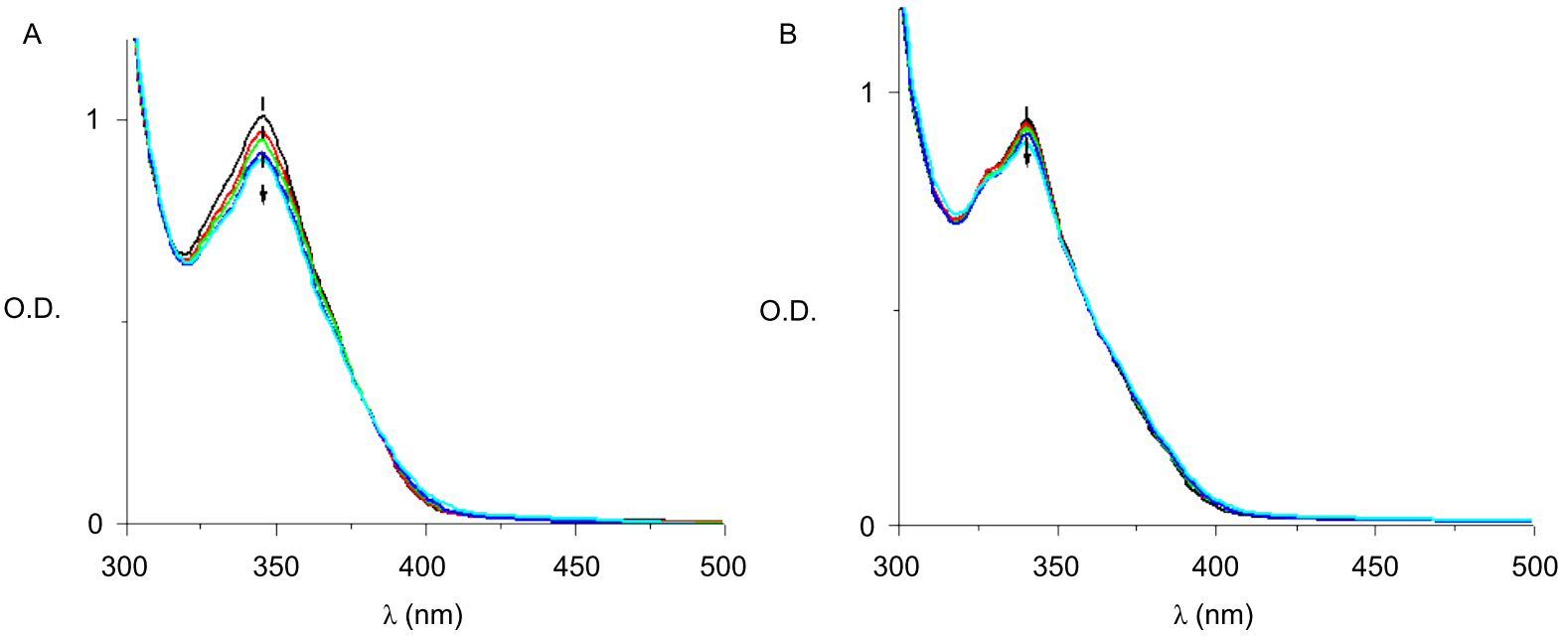

Figure 11: Photolysis of (A) the Py_11/lod and (B) the Py_11/lod/NVK couple. Halogen lamp irradiation. In acetonitrile/toluene (50/50); from $t=0$ to 5 $\min$. 


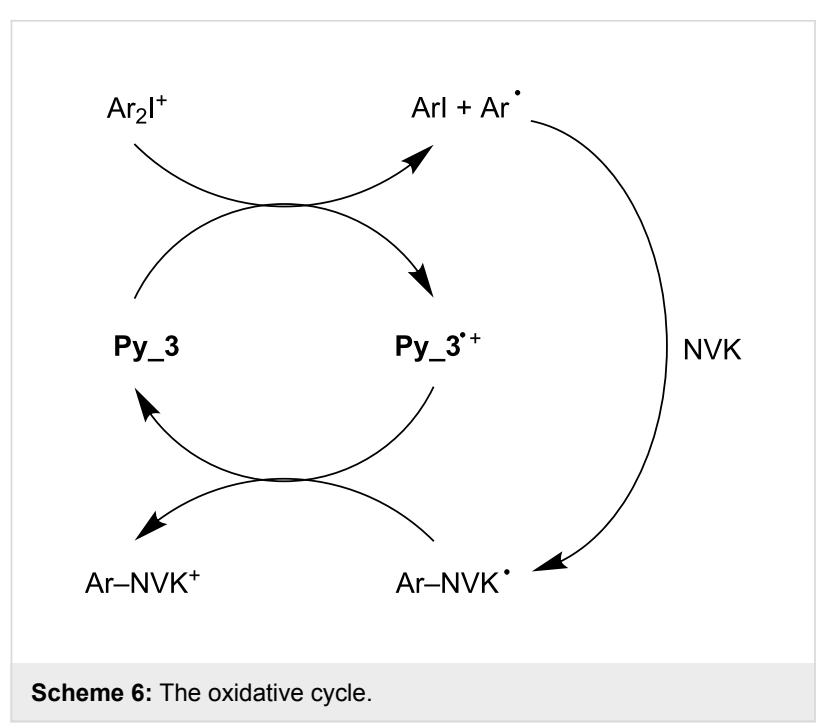

using Py_3). As a consequence, both a reduction and an oxidation cycle could simultaneously proceed (Scheme 7). However, the ESR and polymerization results (see above) (i) suggest that the contribution of the reduction cycle should be weak and (ii) confirm that the regeneration in the oxidation cycle has a low efficiency. This might be due to a $\mathrm{MDEA}^{\bullet+} \rightarrow$ MDEA $_{-\mathrm{H}}{ }^{\circ}$ process (in $\mathrm{r} 8$ in Scheme 5) less efficient than $\mathrm{PBr}^{\bullet}$ $\rightarrow$ phenacyl radical (in $\mathrm{r} 7$ in Scheme 5). Nevertheless, such an oxidation cycle that can contribute here to some extent appears as one of the rare examples observed in photocatalyst $(\mathrm{PC}) / \mathrm{PBr} /$ amine systems, because most of them work according to a reduction cycle [30,46] (see other examples in [47]; in a related system, still unpublished, based on another PC, we have demonstrated the true occurrence of a unique oxidation cycle).

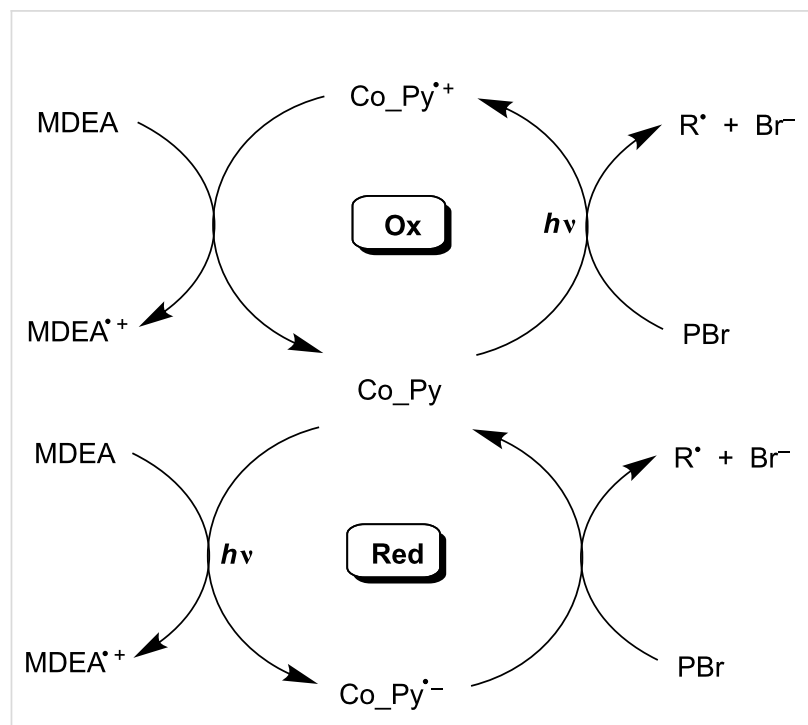

Scheme 7: Oxidation versus reduction cycles.

\section{Conclusion}

In this paper, the core-pyrene $\pi$ structures Co_Pys appear as interesting photoinitiators. Successful cationic and radical photopolymerization reactions were carried out under nearUV-vis irradiation. A photocatalytic behavior is noted, that is, an oxidation cycle for Co_Py/Iod/NVK and a partial oxidation cycle for Co_Py/MDEA/PBr. These experimentally and theoretically investigated di- and trifunctional compounds outline the interest in a suitable strong MO coupling. This could open the way to an a priori choice of absorption spectra driven by the theoretical design of chemical compounds. Other proposals will be provided in the future.

\section{Experimental Co_Pys}

The synthesized compounds are presented in Scheme 3. The procedures are presented in detail in Supporting Information File $1 .{ }^{1} \mathrm{H}$ and ${ }^{13} \mathrm{C}$ NMR spectra and HRMS mass spectral analysis are also given. Py_1 was purchased from Aldrich. 1,4Di(pyren-1-yl)benzene (Py_4) was prepared by adapting a literature procedure [48]. Py_12 was synthesized as previously reported [49]. The syntheses of Py_2 [50], Py_3 [51], Py_6 [52] and Py_7 [53] were already reported under reaction conditions different to the ones reported in this article and in lower yields. The results obtained in our work agree with the previously reported characterization of these products.

\section{Other chemical compounds}

The [methyl-4-phenyl (methyl-1-ethyl)-4-phenyl] iodonium tetrakis(pentafluorophenyl)borate [54,55] (Iod; PI 2074 from Bluestar Silicones - France) was used as the iodonium salt (Scheme 4). Phenacyl bromide (PBr), $N$-methyldiethanolamine (MDEA) and $N$-vinylcarbazole (NVK) were obtained from Aldrich and (4-hydroxyethoxyphenyl) thianthrenium hexafluorophosphate (TH; recrystallized form of Esacure 1187) from Lamberti Spa. The (epoxycyclohexylethyl)methylsiloxanedimethylsiloxane copolymer (EPOX-Si) was obtained from Bluestar Silicones-France (Silcolease UV POLY 200); trimethylolpropane triacrylate TMPTA and (3,4-epoxycyclohexane)methyl 3,4-epoxycyclohexylcarboxylate (EPOX or UVACURE 1500) were provided by Cytec.

\section{Photopolymerization procedures}

TMPTA was irradiated at room temperature under lamination conditions: the formulation ( $25 \mu \mathrm{m}$ thick) is sandwiched between two polypropylene films. The weight percentages for the photoinitiators are given in the figure captions. The evolution of the acrylate content was continuously followed by realtime FTIR spectroscopy (FTIR NEXUS 870 ) at $\sim 1620 \mathrm{~cm}^{-1}$. The formulations ( $25 \mu \mathrm{m}$ thick) based on the cationic monomers (EPOX, EPOX-Si) deposited on $\mathrm{BaF}_{2}$ pellet were irradiated 
under air inside the IR spectrometer cavity at room temperature $[56,57]$. The evolution of the epoxy content was also continuously followed by real-time FTIR spectroscopy (FTIR NEXUS 870). A Xe-Hg lamp (Hamamatsu, L8252, $150 \mathrm{~W}$, filtered light at $\lambda>340 \mathrm{~nm}$; intensity $\sim 30 \mathrm{~mW} / \mathrm{cm}^{2}$ ) and a halogen lamp (intensity $\sim 10 \mathrm{~mW} / \mathrm{cm}^{2}$; the emission spectrum is given in [43]) were used as the irradiation sources.

\section{ESR experiments}

ESR spin-trapping (ESR-ST) experiments were carried out by using a X-Band ESR spectrometer (EMX-plus from Bruker Biospin or MS400 from Magnettech). The radicals were produced at RT under $\mathrm{Xe}-\mathrm{Hg}$ lamp exposure and trapped by phenyl- $N$-tert-butylnitrone (PBN) according to a procedure described in detail in $[58,59]$.

\section{Redox potentials}

The redox potentials were measured in acetonitrile by cyclic voltammetry with tetrabutylammonium hexafluorophosphate $(98 \%)$ as a supporting electrolyte $(0.1 \mathrm{M})$ (Voltalab 6 Radiometer; the working electrode was a platinum disk and the reference a saturated calomel electrode-SCE). Ferrocene was used as a standard and the potentials were determined from half-peak potentials. The free energy change $\Delta G_{\text {et }}$ for an electron-transfer reaction is calculated from the classical Rehm-Weller equation (Equation 1) [60] where $E_{\mathrm{ox}}, E_{\mathrm{red}}, E_{\mathrm{S}}$ and $C$ are the oxidation potential of the donor, the reduction potential of the acceptor, the excited state energy and the coulombic term for the initially formed ion pair, respectively. $C$ is neglected as usually done in polar solvents.

$$
\Delta G_{\mathrm{et}}=E_{\mathrm{ox}}-E_{\mathrm{red}}-E_{\mathrm{s}}+C
$$

\section{Fluorescence experiments}

The fluorescence properties of the different Co_Pys were studied by using a JASCO FP-750 spectrometer.

\section{Computational procedure}

Molecular orbital calculations were done with the Gaussian 03 suite of programs $[61,62]$. The electronic absorption spectra for the different compounds were calculated with the time-dependent density functional theory at B3LYP/6-31G* level on the relaxed geometries calculated at UB3LYP/6-31G* level.

\section{Laser flash photolysis}

Nanosecond laser flash photolysis (LFP) experiments were carried out [26-35] by using a Qswitched nanosecond Nd/YAG laser $\left(\lambda_{\text {exc }}=355 \mathrm{~nm}, 9 \mathrm{~ns}\right.$ pulses; energy reduced down to 10 $\mathrm{mJ}$ ) from Continuum (Minilite) and an analyzing system consisting of a ceramic Xenon lamp, a monochromator, a fast photomultiplier, and a transient digitizer (Luzchem LFP 212).

\section{Supporting Information}

\section{Supporting Information File 1}

Experimental procedures, characterization data, and additional spectra.

[http://www.beilstein-journals.org/bjoc/content/ supplementary/1860-5397-9-101-S1.pdf]

\section{Acknowledgements}

This work was partly supported by the "Agence Nationale de la Recherche" grant ANR 2010-BLAN-0802. JL thanks the Institut Universitaire de France for the financial support.

\section{References}

1. Fouassier, J.-P.; Lalevée, J. Photoinitiators for Polymer Synthesis: Scope, Reactivity and Efficiency; Wiley-VCH: Weinheim, Germany, 2012. doi:10.1002/9783527648245

2. Fouassier, J.-P. Photoinitiation, Photopolymerization, Photocuring; Hanser: Münen, Germany, 1995.

3. Fouassier, J.-P.; Rabek, F. J., Eds. Radiation Curing in Polymer Science and Technology; Chapman \& Hall: London, U.K., 1993.

4. Crivello, J. V.; Dietliker, K. In Photoinitiators for Free Radical, Cationic and Anionic Photopolymerization; Bradley, G., Ed.; Surface Coatings Technology, Vol. III; Wiley/SITA, 1999.

5. Dietliker, K. A. Compilation of Photoinitiators Commercially Available for UV Today; Sita Technology Ltd: London, U.K., 2002.

6. Belfied, K. D.; Crivello, J. V., Eds. Photoinitiated Polymerization; ACS Symposium Series, Vol. 847; American Chemical Society: Washington DC, U.S.A., 2003. doi:10.1021/bk-2003-0847

7. Allen, N. S., Ed. Photochemistry and Photophysics of Polymer Materials; Wiley: Hoboken, 2010.

8. Scranton, A. B.; Bowman, A.; Peiffer, R. W., Eds. Photopolymerization: Fundamentals and Applications; ACS Symposium Series, Vol. 673; American Chemical Society: Washington DC, U.S.A., 1997. doi:10.1021/bk-1997-0673

9. Green, W. A. Industrial Photoinitiators; CRC Press: Boca Raton, 2010. doi:10.1201/9781439827468

10. Mishra, M. K.; Yagci, Y., Eds. Handbook of Vinyl Polymers; CRC Press, 2008.

11. Wang, K.; Jiang, S.; Liu, J.; Nie, J.; Yu, Q. Prog. Org. Coat. 2011, 72, 517-521. doi:10.1016/j.porgcoat.2011.06.011

12. Temel, G.; Enginol, B.; Aydin, M.; Karaca Balta, D.; Arsu, N. J. Photochem. Photobiol., A: Chem. 2011, 219, 26-31. doi:10.1016/j.jphotochem.2011.01.012

13. Wei, J.; Wang, B. Macromol. Chem. Phys. 2011, 212, 88-95. doi:10.1002/macp.201000535

14. Asvos, X.; Siskos, M. G.; Zarkadis, A. K.; Hermann, R.; Brede, O. J. Photochem. Photobiol., A: Chem. 2011, 219, 255-264. doi:10.1016/j.jphotochem.2011.02.028

15. Kabatc, J.; Jurek, K. Polymer 2012, 53, 1973-1980. doi:10.1016/j.polymer.2012.03.027

16. Rosspeintner, A.; Griesser, M.; Pucher, N.; Iskra, K.; Liska, R.; Gescheidt, G. Macromolecules 2009, 42, 8034-8038. doi:10.1021/ma901570h

17. Karaka-Balta, D.; Temel, G.; Goksu, G.; Okal, N.; Arsu, N. Macromolecules 2012, 45, 119-125. doi:10.1021/ma202168m 
18. Yilmaz, G.; Acik, G.; Yagci, Y. Macromolecules 2012, 45, 2219-2224. doi:10.1021/ma3000169

19. Kumbaraci, V.; Aydogan, B.; Talinli, N.; Yagci, Y. J. Polym. Sci., Part A: Polym. Chem. 2012, 50, 2612-2618. doi:10.1002/pola.26034

20. Tunc, D.; Yagci, Y. Polym. Chem. 2011, 2, 2557-2563. doi:10.1039/c1py00269d

21. Kreutzer, J.; Dogan Demir, K.; Yagci, Y. Polym. J. 2011, 47, 792-799.

22. Lalevée, J.; Blanchard, N.; Tehfe, M. A.; Morlet-Savary, F.; Fouassier, J. P. Macromolecules 2010, 43, 10191-10195. doi:10.1021/ma1023318

23. Zhang, G.; Song, I. Y.; Ahn, K. H.; Park, T.; Choi, W. Macromolecules 2011, 44, 7594-7599. doi:10.1021/ma201546c

24. Lalevée, J.; Peter, M.; Dumur, F.; Gigmes, D.; Blanchard, N.; Tehfe, M.-A.; Morlet-Savary, F.; Fouassier, J. P. Chem.-Eur. J. 2011, 17, 15027-15031. doi:10.1002/chem.201101445

25. Tehfe, M.-A.; Ma, L.; Graff, B.; Morlet-Savary, F.; Fouassier, J.-P.; Zhao, J.; Lalevée, J. Macromol. Chem. Phys. 2012, 213, 2282-2286. doi:10.1002/macp.201200489

26. Lalevée, J.; Blanchard, N.; Fries, C.; Tehfe, M. A.; Morlet-Savary, F.; Fouassier, J. P. Polym. Chem. 2011, 2, 1077-1084. doi:10.1039/c0py00392a

27. Tehfe, M.-A.; Zein-Fakih, A.; Lalevée, J.; Dumur, F.; Gigmes, D.; Graff, B.; Morlet-Savary, F.; Hamieh, T.; Fouassier, J. P. Eur. Polym. J. 2013, 49, 567-574. doi:10.1016/j.eurpolymj.2012.10.010

28. Telitel, S.; Lalevée, J.; Blanchard, N.; Kavalli, T.; Tehfe, M.-A.; Schweizer, S.; Morlet-Savary, F.; Graff, B.; Fouassier, J. P. Macromolecules 2012, 45, 6864-6868. doi:10.1021/ma301293m

29. Tehfe, M.-A.; Lalevée, J.; Morlet-Savary, F.; Graff, B.; Blanchard, N.; Fouassier, J. P. ACS Macro Lett. 2012, 1, 198-203. doi:10.1021/mz200140y

30. Tehfe, M.-A.; Lalevée, J.; Morlet-Savary, F.; Graff, B.; Blanchard, N.; Fouassier, J. P. Macromolecules 2012, 45, 1746-1752. doi:10.1021/ma300050n

31. Tehfe, M.-A.; Dumur, F.; Contal, E.; Graff, B.; Morlet-Savary, F.; Gigmes, D.; Fouassier, J. P.; Lalevée, J. Polym. Chem. 2013, 4, 1625-1634. doi:10.1039/c2py20950k

32. Tehfe, M.-A.; Lalevée, J.; Morlet-Savary, F.; Graff, B.; Fouassier, J.-P. Macromolecules 2012, 45, 356-361. doi:10.1021/ma202307x

33. Lalevée, J.; Dumur, F.; Tehfe, M.-A.; Zein-Fakih, A.; Gigmes, D.; Morlet-Savary, F.; Fouassier, J. P. Polymer 2012, 53, 4947-4954. doi:10.1016/j.polymer.2012.08.067

34. Lalevée, J.; Tehfe, M.-A.; Dumur, F.; Gigmes, D.; Blanchard, N.; Morlet-Savary, F.; Graff, B.; Fouassier, J. P. ACS Macro Lett. 2012, 1, 286-290. doi:10.1021/mz2001753

35. Tehfe, M.-A.; Lalevée, J.; Telitel, S.; Sun, J.; Zhao, J.; Graff, B.; Morlet-Savary, F.; Fouassier, J.-P. Polymer 2012, 53, 2803-2808. doi:10.1016/j.polymer.2012.05.009

36. Aydogan, B.; Yagci, Y.; Toppare, L.; Jockusch, S.; Turro, N. J. Macromolecules 2012, 45, 7829-7834. doi:10.1021/ma301546d

37. Aydogan, B.; Durmaz, Y. Y.; Kahveci, M. U.; Uygun, M.; Tasdelen, M. A.; Yagci, Y. Macromol. Symp. 2011, 308, 25-34. doi:10.1002/masy.201151005

38. Aydogan, B.; Gunbas, G. E.; Durmus, A.; Toppare, L.; Yagci, Y. Macromolecules 2010, 43, 101-106. doi:10.1021/ma901858p

39. Bulut, U.; Gunbas, G. E.; Toppare, L. J. Polym. Sci., Part A: Polym. Chem. 2010, 48, 209-213. doi:10.1002/pola.23779

40. Bulut, U.; Balan, A.; Caliskan, C. J. Polym. Sci., Part A: Polym. Chem. 2011, 49, 729-733. doi:10.1002/pola.24485
41. Yagci, Y.; Jockusch, S.; Turro, N. J. Macromolecules 2007, 40, 4481-4485. doi:10.1021/ma070586a

42. Lalevée, J.; Tehfe, M. A.; Dumur, F.; Gigmes, D.; Graff, B.; Morlet-Savary, F.; Fouassier, J. P. Macromol. Rapid Commun. 2013, 34, 239-245. doi:10.1002/marc.201200578

43. Tehfe, M.-A.; Dumur, F.; Graff, B.; Clément, J.-L.; Gigmes, D.; Morlet-Savary, F.; Fouassier, J. P.; Lalevée, J. Macromolecules 2013, 46, 736-746. doi:10.1021/ma3024359

44. Tehfe, M.-A.; Lalevée, J.; Telitel, S.; Contal, E.; Dumur, F.; Gigmes, D.; Bertin, D.; Nechab, M.; Graff, B.; Morlet-Savary, F.; Fouassier, J. P. Macromolecules 2012, 45, 4454-4460. doi:10.1021/ma300760c

45. Magnetic Properties of Free Radicals, Nitroxide Radicals and Nitroxide Based High-Spin Systems. In Landolt-Börnstein - Group II, Molecules and Radicals; Fisher, H., Ed.; Springer Verlag: Berlin, Germany, 2005; Vol. 26d.

46. Narayanam, J. M. R.; Stephenson, C. R. J. Chem. Soc. Rev. 2011, 40, 102-113. doi:10.1039/b913880n

47. Nguyen, J. D.; Tucker, J. W.; Konieczynska, M. D.; Stephenson, C. R. J. J. Am. Chem. Soc. 2011, 133, 4160-4163. doi:10.1021/ja108560e

48. Yang, C.-H.; Guo, T.-F.; Sun, I.-W. J. Lumin. 2007, 124, 93-98. doi:10.1016/j.jlumin.2006.02.003

49. Tehfe, M.-A.; Dumur, F.; Graff, B.; Morlet-Savary, F.; Fouassier, J.-P.; Gigmes, D.; Lalevée, J. Macromolecules 2012, 45, 8639-8647. doi:10.1021/ma301931p

50. Rajakumar, P.; Visalakshi, K.; Ganesan, S.; Maruthamuthu, P.; Suthanthiraraj, S. A. Bull. Chem. Soc. Jpn. 2012, 85, 902-911. doi:10.1246/bcsj.20110280

51. Lee, D.-H.; Jin, M.-J. Org. Lett. 2011, 13, 252-255. doi:10.1021/ol102677r

52. Kim, M. K.; Kwon, J.; Hong, J. P.; Lee, S.; Hong, J. I. Bull. Korean Chem. Soc. 2011, 32, 2899-2905. doi:10.5012/bkcs.2011.32.8.2899

53. Ishi-i, T.; Yaguma, K.; Thiemann, T.; Yashima, M.; Ueno, K.; Mataka, S. Chem. Lett. 2004, 33, 1244-1245. doi:10.1246/cl.2004.1244

54. Castellanos, F.; Fouassier, J. P.; Priou, D.; Cavezzan, A. Onium borates/borates of organometallic complexes and cationic initiation of polymerization therewith. U.S. Patent 5,668,192, Sept 16, 1997.

55. Castellanos, F.; Fouassier, J. P.; Priou, C.; Cavezzan, J. J. Appl. Polym. Sci. 1996, 60, 705-713. doi:10.1002/(SICI)1097-4628(19960502)60:5<705::AID-APP7>3.0.CO; $2-U$

56. Tehfe, M.-A.; Lalevée, J.; Gigmes, D.; Fouassier, J. P. Macromolecules 2010, 43, 1364-1370. doi:10.1021/ma9025702

57. Tehfe, M.-A.; Lalevée, J.; Gigmes, D.; Fouassier, J. P. J. Polym. Sci., Part A: Polym. Chem. 2010, 48, 1830-1837. doi:10.1002/pola.23956

58. Tordo, P. Spin-trapping: recent developments and applications. In Electron Pragmagnetic Resonance; Gilbert, B. C.; Atherton, N. M.; Davies, M. J., Eds.; The Royal Society of Chemistry: Cambridge, U. K., 1998; Vol. 16.

59. Lalevée, J.; Dumur, F.; Mayer, C. R.; Gigmes, D.; Nasr, G.; Tehfe, M.-A.; Telitel, S.; Morlet-Savary, F.; Graff, B.; Fouassier, J. P. Macromolecules 2012, 45, 4134-4141. doi:10.1021/ma3005229

60. Rehm, D.; Weller, A. Isr. J. Chem. 1970, 8, 259-271.

61. Gaussian 03, Revision B2; Gaussian, Inc.: Wallingford, CT, 2003.

62. Foresman, J. B.; Frisch, A. Exploring Chemistry with Electronic Structure Methods, 2nd ed.; Gaussian, Inc.: Wallingford, CT, 1996. 


\section{License and Terms}

This is an Open Access article under the terms of the Creative Commons Attribution License

(http://creativecommons.org/licenses/by/2.0), which permits unrestricted use, distribution, and reproduction in any medium, provided the original work is properly cited.

The license is subject to the Beilstein Journal of Organic Chemistry terms and conditions:

(http://www.beilstein-journals.org/bjoc)

The definitive version of this article is the electronic one which can be found at:

doi:10.3762/bjoc.9.101 